\title{
Evaluation of a standardized hyperglucidic breakfast test in postprandial reactive hypoglycaemia
}

\author{
J.F. Brun, C. Fédou, O. Bouix, E. Raynaud, A. Orsetti \\ Service d'Exploration Physiologique des Hormones et des Métabolismes, Hôpital Lapeyronie, Montpellier, France
}

\begin{abstract}
Summary The oral glucose tolerance test is not specific for diagnosing postprandial reactive hypoglycaemia, since it too frequently induces low blood glucose values in subjects who have never complained of symptoms of this. By contrast, the mixed meal tests are deceptive for this purpose because they do not induce hypoglycaemia in subjects who have complained of of hypoglycaemic symptoms. We investigated the frequency of hypoglycaemia after a standardized hyperglucidic breakfast test in three groups of subjects:group A, 43 control subjects; group B, 38 postprandial reactive hypoglycaemic patients; group C, 1193 asymptomatic subjects undergoing assessment of glycoregulation. In the 38 subjects with suspected reactive hypoglycaemia the mean blood glucose nadir was $3.48 \pm 0.08 \mathrm{mmol} / 1$, i. e. lower than in control subjects $(4.83 \pm 0.13 p<0.0001)$. Blood glucose levels less than $3.3 \mathrm{mmol} / 1$ were found in $47.3 \%$ of subjects with suspected postprandial reactive
\end{abstract}

hypoglycaemia (group B), i.e more frequently than in control subjects (group A: $2.2 \% p=1.6 \times 10^{-6}$ ) and asymptomatic subjects (group C: $1 \% p=8 \times$ $10^{-22}$ ). This markedly higher frequency of low blood glucose values in subjects with postprandial symptoms compared with control and asymptomatic subjects suggests that this test detects a tendency to hypoglycaemia after a standardized hyperglucidic breakfast. Since this test mimics average French eating habits, the results suggest that the patients undergo such symptoms in their everyday life, and that the hyperglucidic breakfast test is a simple alternative to ambulatory glucose sampling for diagnosis of postprandial reactive hypoglycaemia. [Diabetologia (1995) 38: 494-501]

Key words Mixed meal, oral glucose tolerance test, reactive hypoglycaemia.
Postprandial reactive hypoglycaemia ( $\mathrm{PRH})$ is a controversial syndrome, since its symptoms are not specific and correlate weakly with blood glucose concentrations measured after a glucose load $[1,2]$. The syndrome cannot be diagnosed unless the correct criteria are applied [3]. The classic oral glucose tolerance test (OGTT) is frequently used by physicians to diagnose this condition; however, this has been demonstrated

Received: 6 June 1994 and in final revised form: 8 November 1994

Corresponding author: Dr. J.F. Brun, Service d'Exploration Physiologique des Hormones et des Métabolismes, Hôpital Lapeyronie, F-34059 Montpellier-cédex, France

Abbreviations: PRH, Postprandial reactive hypoglycaemia; OGTT, oral glucose tolerance test. to be unreliable in this context, since blood glucose often decreases below the starting values in the late phases of this test, even in subjects with no history of PRH. For example Lev Ran and Anderson. [5] reported that $25 \%$ of patients with no signs of $\mathrm{PRH}$ reached values lower than $3 \mathrm{mmol} / \mathrm{l}$. Chemical hypoglycaemia may occur as often in control subjects as in patients referred because of possible hypoglycaemic symptoms $[5,6]$. Thus, a low blood glucose value during OGTT does not mean that the subject is prone to hypoglycaemia in everyday life [4]. Consensus conferences have emphasized that this diagnosis should not be made by OGTT but by the measurement of a low blood glucose value observed simultaneously with the signs of the syndrome [3]. Ambulatory blood glucose control [7] is a satisfacto- 
ry solution and has been used successfully. It has shown that $46 \%$ of a group of 28 patients with this complaint did have blood glucose values lower than $3.3 \mathrm{mmol} / 1$ during postprandial symptoms. Moreover, $18 \%$ had glycaemia lower than $2.8 \mathrm{mmol} / \mathrm{l}$. Unfortunately, this procedure is difficult to perform under routine conditions. A possible alternative would be a standard mixed meal reproducing the normal nutritional habits of the subjects: if hypoglycaemia could be induced, it could be concluded that the subject may experience hypoglycaemia during their everyday life. Unfortunately, some trials with standard mixed meals have given unreliable results $[5,8,9]$, leading to the conclusion that these patients do not experience hypoglycaemia after such a meal. Since PRH can be prevented with a diet correcting excessive carbohydrate intake [10], we hypothesized that the meals used in these studies were too equilibrated, and to some extent compensate for the abnormality responsible for hypoglycaemia; therefore the test was unable to detect the disease. A more 'hyperglucidic' standardized breakfast, which could both mimic the French nutritional habits and represent a strong glucose stimulus, might avoid some pitfalls of both the OGTT and the too- equilibrated mixed meals for this purpose. Thus, our working hypothesis was that PRH is not infrequent, but an adequate tool for diagnosis is still missing. If a subject underwent an exaggerated fall in blood glucose after such a breakfast, it would be reasonable to assume that they may suffer from a similar fall (with its clinical symptoms) during everyday life.

\section{Subjects and methods}

Subjects. Two groups of subjects were compared in this experiment. Group A, 43 volunteer control subjects of normal weight (9 males and 34 females; age: 23 to 49 years; weight: $55-77 \mathrm{~kg}$; height: $156-179 \mathrm{~cm}$ ); group $\mathrm{B}, 38$ subjects with suspected $\mathrm{PRH}$ reporting two or more of the postprandial signs listed in the questionnaire presented in this paper ( 4 males, 34 females; age: 20-54 years.; weight: 48-85 kg; height: $146-173 \mathrm{~cm}$ ). None of the subjects in either group were taking medication at the time of the investigation. In addition, we had the opportunity to perform the hyperglucidic breakfast test in a large series of subjects who came to our outpatient unit for a nutritional check-up in which this test was used to assess glycoregulation. These subjects attended for dietary counselling due to moderate obesity. A group of such subjects was selected and referred to as group C. They consisted of 1193 subjects with no symptoms suggestive of PRH (473 males and 720 females; age, 17-62 years; weight, 50-89 kg; height, 154-181 cm). For all groups pituitary, thyroid, and adrenal causes of hypoglycaemia were excluded. No patient had insulinoma or either partial or total gastrectomy. Markedly obese subjects (body mass index $>31 \mathrm{~kg} \cdot \mathrm{m}^{-2}$ ) and patients with impaired glucose tolerance according to the World Health Organization criteria were excluded from the study. Exclusion of glucose tolerance abnormalities was made by previous OGTT or blood glucose measurements if they were available, or from the results of the breakfast test. All subjects gave their informed consent.
Hyperglucidic breakfast test. No dietary restriction was imposed; however, subjects were asked to fast for $12 \mathrm{~h}$ before starting the test at 8.30 hours. A cannula for blood sampling was placed in the cephalic vein at the level of the cubital fossa. The subjects ate the standardized breakfast which was composed of bread ( $80 \mathrm{~g})$, butter $(10 \mathrm{~g})$, jam $(20 \mathrm{~g})$, skimmed concentrated milk ( $80 \mathrm{ml})$ (Gloria SA, Paris, France), sugar (10 g) and powdered coffee $(2.5 \mathrm{~g})$. The breakfast thus comprised 2070 kilojoules with $9.1 \%$ protein, $27.5 \%$ lipid, and $63.4 \%$ carbohydrate. The average time for consuming the meal was $6 \mathrm{~min}$. Blood samples were taken twice before the meal and at $15,30,60,90,120,150,180,210,240,270,300 \mathrm{~min}$ following the start of the meal. A preliminary blood glucose evaluation at each of these times was made with a glucose analyser (glucometer 3; Ames Bayer Diagnostics, Puteaux, France). If a tendency to a fall in blood glucose was detected, patients were observed more closely for onset of symptoms. If blood glucose levels at the end of the test were still decreasing, blood continued to be drawn every $30 \mathrm{~min}$ until levels returned to baseline. An investigator remained with the patient and if hypoglycaemic symptoms were mentioned, they were noted on a questionnaire (and compared to the signs reported to occur spontaneously) and an additional blood sample was taken.

Comparison between the hyperglucidic breakfast test and a classic mixed meal. An equilibrated mixed meal was compared to the hyperglucidic breakfast. Its composition was calculated to correspond to the average of the three breakfast tests described in the literature which have not been shown to induce hypoglycaemia in patients referred for suspicion of PRH [5, 8 , 9]. This breakfast comprised bread ( $40 \mathrm{~g}$ ), two eggs, powdered skimmed milk (14.5 g, SACM, Hochfelden, France which is composed of $14 \%$ fat, $31 \%$ protein and $43.2 \%$ lactose), sugar $(5 \mathrm{~g})$ and rice krispies ( $25 \mathrm{~g}$, comprising $86 \%$ carbohydrates, $6 \%$ proteins, and $1 \%$ lipids). The breakfast thus comprised 2030 kilojoules with $21.4 \%$ protein, $30.3 \%$ lipids, and $48 \%$ carbohydrates. Blood was drawn twice before the meal and at $15,30,60,90,120,150,180 \mathrm{~min}$ following the start of the meal. This test was compared with the hyperglucidic breakfast described above in six healthy subjects (three males, three females, age 22-26 years, height 170-174 cm; weight $57-65 \mathrm{~kg}$ ). Tests were performed at random order with a 1-week interval.

Questionnaire. A standardized questionnaire for symptoms of hypoglycaemia according to the symposium of Rome [3] was presented to the subject if he/she mentioned postprandial symptoms. The symptoms occurring in everyday life were also asked for, and compared to symptoms occurring during the breakfast test. We looked for signs of neuroglucopenia: blurred vision, headache, confusion, depression, paraesthesia; and sympathetic signs: tremours, anxiety, hunger, palpitations, sweating, nausea, dizziness and weakness. Patients were asked to score all these symptoms from 0 to five, five being the most severe.

Laboratory measurements. All samples were analysed for plasma insulin by a radioimmunoassay (kit SB-INSI-1 from Sorin Biomedica, Saluggia, Italy) and plasma glucose with a Beckman glucose analyser (Beckman Instruments, Brea, Calif., USA). The within assay coefficient of variation (CV) for insulin was determined by repeated measurements of the same sample and was between $8.6 \%$ (low values) and $9.7 \%$ (high values). The between assay $\mathrm{CV}$ for insulin was between $12.5 \%$ (low values) and $14.4 \%$ (high values). The sensitivity (lowest detectable value) was $2 \mu \mathrm{U} / \mathrm{ml}$.

Homeostasis model assessment (HOMA). An attempt to evaluate insulin sensitivity and beta-cell responsiveness was made with the homeostasis model assessment (HOMA), a simple 


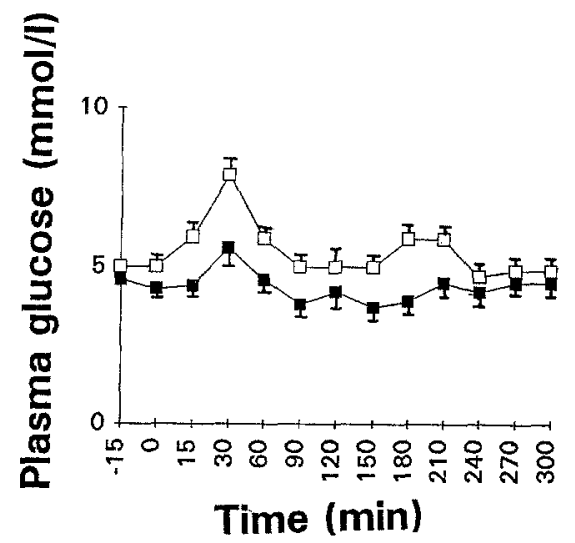

Fig. 1. Blood glucose response to the breakfast tolerance test in patients referred for postprandial hypoglycaemia (group B, $n=38$, lower curve) compared to 43 control subjects (group A). Values given as mean \pm SEM. No significant difference between groups

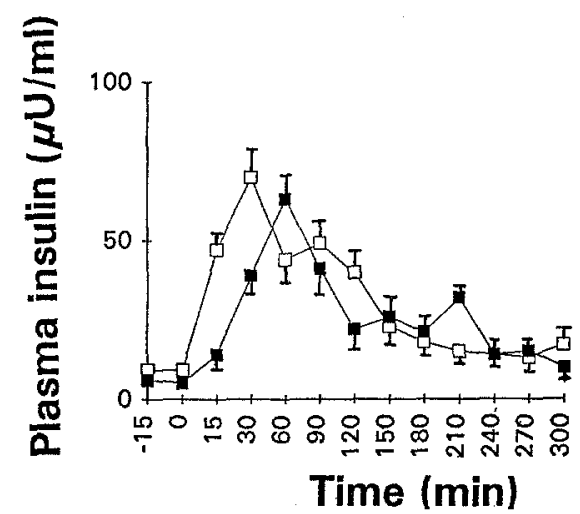

Fig. 2. Insulinaemic response to the breakfast tolerance test. Group A (43 control subjects) $\square$; group B (38 subjects with symptoms of postprandial reactive hypoglycaemia) $\square$.Values given as mean \pm SEM. No significant difference between the two groups

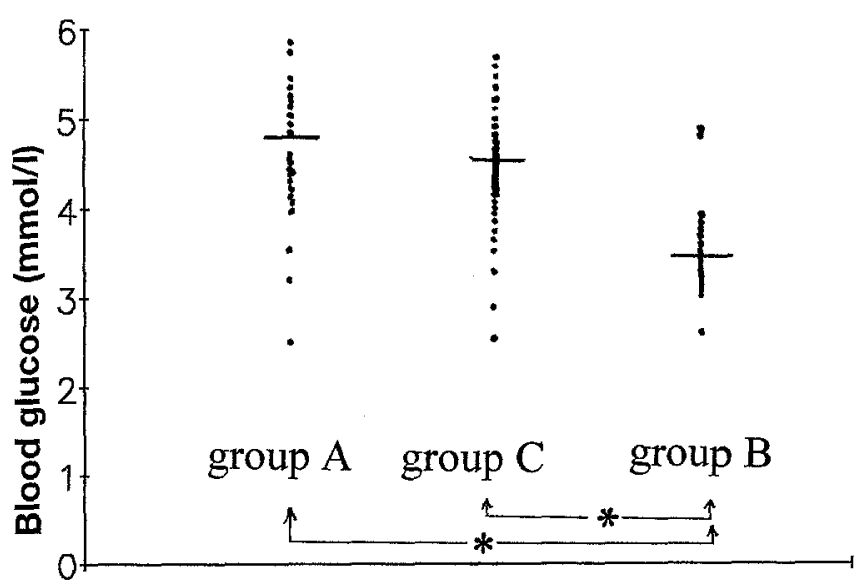

Fig. 3. Nadirs of blood glucose values measured after the hyperglucidic breakfast test in groups A (control subjects), B (suspicion of postprandial reactive hypoglycaemia) and in an additional goup C of 1193 patients with no postprandial signs. The 38 subjects of group B have a lower mean blood glucose nadir than the other groups $\left({ }^{*} p<0.0001\right)$
J.F. Brun et al.: Hyperglucidic breakfast in reactive hypoglycaemia

calculation which has been validated in comparison with the euglycaemic clamp [11]. The insulin resistance index is defined as insulin/(22.5e $\left.\mathrm{e}^{\text {-ln glucose }}\right)$ and beta-cell function is equal to $20 \times$ insulin/(glucose- $3.5 \mathrm{mmol} / \mathrm{h})$. The lowest of the two baseline values before the breakfast test was employed for this calculation.

\section{Statistical analysis}

All data are expressed as means \pm SEM. Statistical analyses employed one-way analysis of variance (ANOVA) to ascertain significance among multiple means, with the NewmanKeuls interpretation of individual significant effects. Frequency comparisons were performed with Fisher's exact test. The null hypothesis was, as usual, rejected for $p$ values of less than $5 \%$.

\section{Results}

Response to the breakfast tolerance test. Glycaemic and insulinaemic responses in the groups $\mathrm{A}$ and $\mathrm{B}$ during the breakfast tolerance test are shown on Figures 1 and 2. Insulin responses were not significantly different. Blood glucose responses on the whole did not exhibit significant differences, but there was a non-significant tendency to find lower blood glucose values in group B, i.e. subjects investigated for postprandial symptoms.

Blood glucose nadirs during the test. In the 38 subjects explored for suspected reactive hypoglycaemia the mean nadir of glycaemia was $3.48 \pm 0.08 \mathrm{mmol} / 1$, i. e. lower than in control subjects $(4.83 \pm 0.13 p<$ 0.0001), as shown in Fig.3.

Time at which insulin and glucose peaks and nadirs occur. The glucose peak occurred at a mean time of $43.42 \pm 5.24 \mathrm{~min}$ in group A (control subjects) and at $35.55 \pm 2.21 \mathrm{~min}$ in group B (suspicion of PRH). In group C (1193 asymptomatic patients), this peak was found at $45.6 \pm 0.77 \mathrm{~min}$. There was no difference between $\mathrm{A}$ and $\mathrm{B}$, or between $\mathrm{A}$ and $\mathrm{C}$, but this peak occurred significantly earlier in $\mathrm{B}$ than in $\mathrm{C}(p<0.03)$. The lowest blood glucose value occurred at a mean time of $165.62 \pm 3.65 \mathrm{~min}$ in group $\mathrm{A}$ and at $171.15 \pm 8.31 \mathrm{~min}$ in group B. However, it occurred at $160.91 \pm 1.16 \mathrm{~min}$ in group C. There was no statistically significant difference among these times. The highest insulin value occurred at a mean time of $61.15 \pm 4.79 \mathrm{~min}$ in group $\mathrm{A}$ and at $67.22 \pm 6.33 \mathrm{~min}$ in group B. For comparison it occurred at $71.667 \pm 1.67 \mathrm{~min}$ in group $\mathrm{C}$. These times were not different.

Frequency of low blood glucose values in the three groups. As shown in Table 1, frequency of blood glucose lower than $2.8 \mathrm{mmol}$ was not different in the 
Table 1. Frequency of low blood glucose level nadirs during the hyperglucidic breakfast test in the three groups of subjects of the study

\begin{tabular}{llc}
\hline & \multicolumn{2}{l}{ Blood glucose nadir } \\
\hline & $<2.8 \mathrm{mmol}$ & $<3.3 \mathrm{mmol}$ \\
\hline Control subjects $(n=43)$ & $1(2.2 \%)$ & $1(2.2 \%)^{\mathrm{a}}$ \\
Signs of hypoglycaemia $(n=38)$ & $1(2.6 \%)$ & $18(47.3 \%)$ \\
$\begin{array}{l}\text { No sign of hypoglycaemia } \\
(n=1193)\end{array}$ & $1(0.08 \%)$ & $12(1 \%)^{\mathrm{b}}$ \\
\hline
\end{tabular}

Comparison (Fisher's exact test). ${ }^{\text {a }}$ Group B (suspected hypoglycaemia) vs control subjects: $p=1.6 \times 10^{-6}$; ${ }^{b}$ group B (suspected hypoglycaemia) vs subjects explored for a routine check-up of glycoregulation without any complaint of postprandial signs: $p=8 \times 10^{-22}$

three groups. In group B (subjects with suspicion of PRH $n=38)$ there was only one case $(2.6 \%)$; in group A (control subjects $n=43$ ) only one $(2.2 \%)$ and in group C (asymptomatic subjects $n=1193$ ) only one $(0.08 \%)$. There was no statistical difference among these three groups. Frequency of blood glucose levels lower than $3.3 \mathrm{mmol}$ was as follows. In group B $(n=38)$ there were 18 cases $(47.3 \%)$; in group $\mathrm{A}(n=43)$ only one $(2.2 \%)$ and in group $\mathrm{C}$ $(n=1193) 12(1 \%)$. There was no difference between group $\mathrm{A}$ and group $\mathrm{C}$ in frequency. By contrast subjects from group $\mathrm{B}$ (suspicion of hypoglycaemia) had a significantly higher frequency of blood glucose values lower than $3.3 \mathrm{mmol} / 1$ than either group $\mathrm{A}\left(p=1.6 \times 10^{-6}\right)$ or group $\mathrm{C}\left(p=8 \times 10^{-22}\right)$.

Homeostasis model assessment. The homeostasis model assessment showed a lower insulin resistance index (i.e. a higher insulin sensitivity) in group B than group $\mathrm{A}(1.71 \pm 0.13$ vs $2.29 \pm 0.74, p<0.01)$. The beta-cell function index was lower in $B$ $(185.3 \pm 20.39)$ compared to A $(278.72 \pm 27.14$, $p<0.01)$.

Hypoglycaemic symptoms during the test. Frequency of symptoms in the questionnaire was assessed in groups A and B. In A (control subjects), no symptoms were noted on the questionnaire. In group B 10 subjects noted symptoms on the standardized list, i. e. an occurrence of symptoms markedly lower than the frequency of low blood glucose values $\left(p=6.37 \times 10^{-2}\right)$, but a significantly higher frequency than in group A $\left(p=5.03 \times 10^{-4}\right)$. Among signs of neuroglucopenia, headache (once) and paraesthesias (twice) were reported. Among sympathetic signs, anxiety (twice), hunger (four times), palpitations (once), sweating (once), nausea (once), dizziness (twice) and weakness (twice) were noticed.

Comparison between the hyperglucidic breakfast and the classic mixed meal (Table 2). Comparison of blood glucose and insulin values over the $180 \mathrm{~min}$ fol-

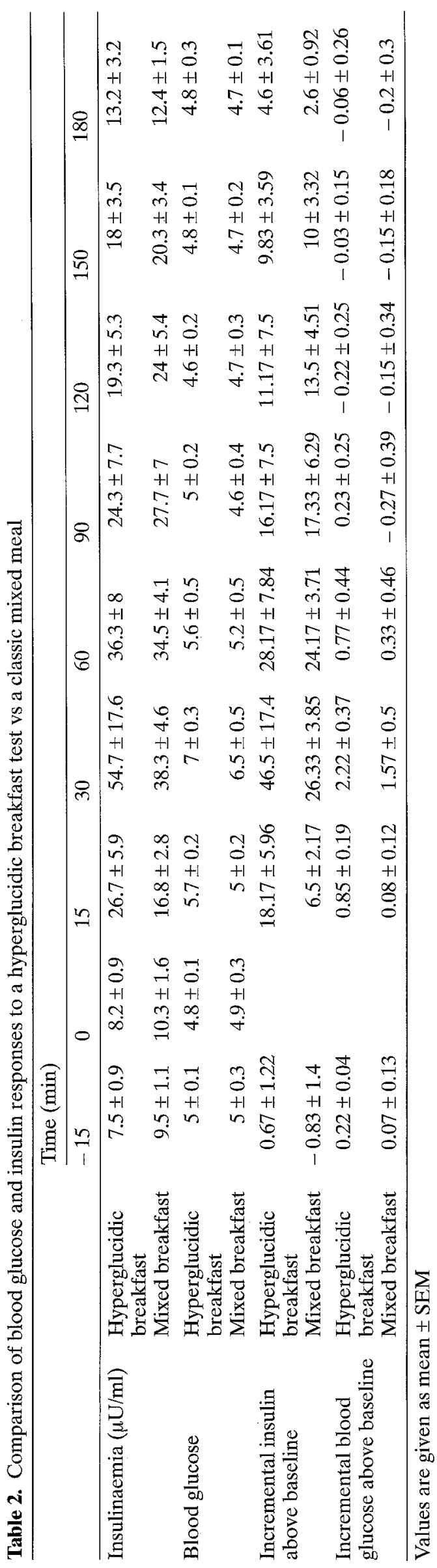


lowing these two breakfast tests did not show any significant difference. However, when comparing only values between 0 and $90 \mathrm{~min}$ the ANOVA detected higher blood glucose values in the hyperglucidic breakfast test $(p<0.01)$. The area under the blood glucose curve over $180 \mathrm{~min}$ was $948.24 \pm 24.80 \mathrm{mmol} /$ $1 \times 180 \mathrm{~min}$ after the hyperglucidic breakfast vs 900.7253 .88 (NS) after the mixed breakfast. The area under the blood glucose curve over $120 \mathrm{~min}$ was $667.4 \pm 29.03 \mathrm{mmol} / 1 \times 120 \mathrm{~min}$ after the hyperglucidic breakfast vs $624.2 \pm 37.36$ (NS) after the mixed breakfast. When incremental blood glucose values above baseline were compared, there was a highly significant difference between the two curves $(p<0.001)$ over $180 \mathrm{~min}$, indicating a higher glucose response in the hyperglucidic test. The NewmansKeuls procedure allowed a more precise location of the significant difference between 60 and $90 \mathrm{~min}$ $(p<0.01)$. There was a non-significant tendency to a higher integrated plasma glucose concentration above baseline after the hyperglucidic test $(89.1 \pm 26.27 \mathrm{mmol} / 1 \times 180 \mathrm{~min}$ vs $36.32 \pm 33.21$, NS $)$. Similarly the incremental plasma glucose value during the first $120 \mathrm{~min}$ of the test was not different although a non-significant tendency can be described $(80.93 \pm 31.24$ vs $15.62 \pm 50.22)$. The area under the insulinaemia curve over $180 \mathrm{~min}$ was $4675.2 \pm$ $1418.86 \mathrm{mmol} / \mathrm{l} \times 180 \mathrm{~min}$ after the hyperglucidic breakfast vs $3943.4 \pm 425.35$ (NS) after the mixed breakfast. The area under the insulinaemia curve over $120 \mathrm{~min}$ was $667.4 \pm 29.03 \mathrm{mmol} / \mathrm{l} \times 120 \mathrm{~min}$ after the hyperglucidic breakfast vs $624.2 \pm 37.36$ (NS) after the mixed breakfast. Incremental insulin responses were not statistically different, although there was a non-significant tendency to a higher integrated insulin concentration above baseline after the hyperglucidic test $(3178.3 \pm 1386.72 \times 180 \mathrm{~min}$ vs $2143.4 \pm 136.68 \mu \mathrm{U} / \mathrm{ml}$, NS). Similarly the incremental insulin value during the first $120 \mathrm{~min}$ of the test was not different $(2898.58 \pm 953.15$ vs $1868.37 \pm$ 551.53).

Calculations were made to compare the insulinogenic effect of increments in blood glucose levels after both tests. The ratio of the maximal insulin increment on the maximal blood glucose increment did not statistically differ $(21.02 \pm 4.38 \mu \mathrm{U} /$ $\mathrm{mmol} \times 10^{3}$ for the hyperglucidic breakfast vs $30.12 \pm 11.34$ for the mixed breakfast), neither did the ratio of the maximal insulin value on the maxi$\mathrm{mal}$ glucose value $\left(7.93 \pm 2.065 \mu \mathrm{U} / \mathrm{mmol} \times 10^{3}\right.$ for the hyperglucidic breakfast vs $6.55 \pm 0.81$ for the mixed breakfast).

\section{Discussion}

The standardized breakfast test which has been used in this study is derived from the test developed by Le- fèbvre and Luyckx [12]. We introduced some modifications in meal composition in order to fit with average French habits. In particular, the usual French breakfast is less equilibrated and mostly composed of carbohydrates [13]. The quantity of carbohydrates (76 g) was chosen in order to obtain a similar increase in blood glucose as during a standard $75 \mathrm{~g}$ OGTT. We reported elsewhere that this breakfast tolerance test, in obese subjects, induces the same increase in blood glucose as OGTT [14].

The main finding of this study is that, with this 'hyperglucidic' breakfast test, our 38 subjects investigated for PRH exhibit $47.3 \%$ lower blood glucose values than $3.3 \mathrm{mmol} / \mathrm{l}$. This frequency is similar to the results obtained by Palardy et al. [7] who, using ambulatory glycaemic autocontrol reported blood glucose levels lower than $3.3 \mathrm{mmol} / \mathrm{l}$ during symptoms 28 patients. Thus, it seems likely that this breakfast test detects a tendency to low blood glucose values, in such patients, with the same frequency as ambulatory blood glucose measurements. By contrast, such low values are extremely rare with this test in control subjects and in subjects with no postprandial symptoms, while in OGTT a poststimulative hypoglycaemia is very usual $[3,5,15]$.

However, one could argue that $3.3 \mathrm{mmol} / 1$ represents a moderate hypoglycaemia. Several authors have been more restrictive in their definition of hypoglycaemia and give a cut-off value of 2.8 or $2.2 \mathrm{mmol} / \mathrm{l}$ $[5,6]$. Clearly, our hyperglucidic breakfast test does not induce values of blood glucose lower than $2.8 \mathrm{mmol} / 1$ with an increased frequency in patients referred for signs of hypoglycaemia. This cut-off value at $2.8 \mathrm{mmol} / 1$ has been proposed in order to avoid the overdiagnosis of PRH which occurs frequently [1-3]. However, there is a large body of evidence that plasma glucose values between 3.3 and $2.8 \mathrm{mmol} / 1 \mathrm{can}$ induce symptoms of hypoglycaemia. Blood glucose values between 3.6 and $2.6 \mathrm{mmol} / \mathrm{l}$ are associated with a detectable impairment in cognitive functions [16] and in some complex performances such as driving a car [17]. The threshold for symptoms of hypoglycaemia is generally close to $3.3 \mathrm{mmol} / \mathrm{l}: \quad 3.6 \mathrm{mmol} / 1 \quad[18] ; \quad 3.4 \mathrm{mmol} / 1 \quad$ [19]; $3.3 \mathrm{mmol} / 1$ [9]; $3.3 \mathrm{mmol} / 1$ [7]. On arterialized blood [20] there seems to be a 'hierarchy' of thresholds: $3.9 \mathrm{mmol} / 1 \mathrm{counterregulation;} 3.3 \mathrm{mmol} / 1$ sympathetic response; $2.8 \mathrm{mmol} / 1$ neuroglucopenic symptoms. When blood glucose is maintained at fixed values by the glucose clamp technique, hypoglycaemic thresholds for autonomic and neuroglycopenic signs in healthy individuals are between 4.5 and $3 \mathrm{mmol} / 1$ in arterialized blood [21]. It should be pointed out that in this paper we did not measure blood glucose levels on arterialized blood, as was generally done in the studies mentioned above [21-22]. Our goal was to propose a practical, simple test, and the use of arterialized blood would not facilitate its applica- 
tion. Thus, we chose to evaluate blood glucose levels on venous plasma, under routine endocrine test conditions. Values of $3.3 \mathrm{mmol} / \mathrm{l}$ in venous plasma may correspond to values above $4 \mathrm{mmol} / 1$ in arterialized blood; i.e. they remain within the zone where the hypoglycaemic thresholds are usually found. Furthermore, orthostatic position rather than recumbency [22], as well as the particular psychology of this kind of patient [6] may amplify the symptoms. In a recent review on this subject, PJ Lefebvre writes: "at plasma glucose values around $3.2 \mathrm{mmol} / \mathrm{l}$, palpitations, tremour and sweating may be slightly uncomfortable" [23]. Thus, although the values of hypoglycaemia in our test do not generally reach the classic cut-off value of $2.8 \mathrm{mmol} / 1$, we think that their occurrence subjects referred for PRH, given that that they very rarely occur in control subjects and that they are able to induce symptoms, are suggestive for the diagnosis of moderate, reactive hypoglycaemic events.

The low frequency of hypoglycaemic symptoms during the chemical hypoglycaemias in our breakfast test deserve comment. The consensus statements [3, 23 insist on the need to clearly demonstrate the simultaneous occurrence of symptoms and low blood glucose values for diagnosing PRH. Clearly, this is a fundamental point when using the OGTT or glycaemic ambulatory control for this purpose, since the OGTT gives too many false- positive results and glycaemic control aims at observing the spontaneous event itself. However, it is not surprising to find a lower frequency of symptoms during our breakfast test. The conditions of this test are not exactly the conditions of the spontaneous PRH. Composition of the hyperglucidic breakfast is standardized, and in some PRH patients the meals could be less balanced, thus inducing a stronger hypoglycaemia with more pronounced symptoms. In addition, the sympathetic response could be reduced by resting and recumbency, as discussed above. Thus, we think that the novelty of this breakfast test is rather to expose a chemical hypoglycaemia (an otherwise very rare event) during the test, than to totally mimic the spontaneous hypoglycaemia with all its symptoms.

Almost half of our group of 38 subjects (group B) referred with PRH have a blood glucose nadir lower than $3.3 \mathrm{mmol} / \mathrm{l}$ and thus are likely to also present low blood glucose values after meals in their everyday life. In this study, home monitoring of blood glucose levels with a glucose analyser was not systematically done, but in three of these subjects it showed low blood glucose levels $(<2.8 \mathrm{mmol} / \mathrm{l})$. Probably, most of our subjects with a low glycaemic nadir after the breakfast test are such bona fide hypoglycaemic patients. The complex postprandial coordination of a decrease in insulinaemia and an increase in counterregulatory hormones $2-3 \mathrm{~h}$ after a meal has been shown to be occasionally deficient. The more classic mechanism is postprandial hyperinsulinism, demon- strated many years ago by Luyckx and Lefèbvre [15]. Obviously, an increased insulin response is the explanation for the excessive decrease in blood glucose in several of our patients. However, in this series, the comparison of insulin responses does not show a marked difference, suggesting hyperinsulinism is not the most important mechanism in this sample. More recently, increased insulin sensitivity has also been found in such patients with the glucose clamp [24] and the minimal model [25]. An increased non-oxidative glucose metabolism has been shown to be involved in this process [26]. Interestingly, when calculating a simple insulin sensitivity index in our patients with the homeostasis model assessment, we also found that this sensitivity was enhanced in patients with PRH. A parallel reduction in the betacell function index provided by this model may indicate that during fasting there is a compensatory decrease in insulin release, consistent with the concept of a feedback loop between insulin sensitivity and insulin release [27]. Increased insulin sensitivity is possibly a frequent cause of PRH $[25,26]$. A third mechanism, which remains poorly understood, is the possible involvement of moderate defects in glucose counterregulation [23]. For instance, a lowered glucagon response [28] has been reported, although this has not been investigated here. Probably, bona fide hypoglycaemia is an heterogeneous condition in which one or several of these abnormalities may be found. The hyperglucidic breakfast test may be a simple tool to assess this multifactorial condition, under physiological conditions. However, more than $50 \%$ of the patients selected on the basis of signs of PRH do not show this abnormal blood glucose nadir lower than $3.3 \mathrm{mmol} / \mathrm{l}$. Many of these subjects are probably "non-hypoglycaemic" patients, i.e. suffering from sympathetic signs after a meal without any postprandial blood glucose decrease [1, 3, 23]. However, some "false negative" responses cannot be excluded, i.e. subjects who undergo hypoglycaemia during their everyday life and do not show this low nadir after the hyperglucidic breakfast.

Another question is why this breakfast detected a particular glycaemic pattern in patients with suspected PRH, while breakfasts administered by other authors $[4,8,9]$ did not. Composition of the diverse breakfast tests employed in the literature markedly differs. Compared to the breakfast tests of previous investigators our test is more hyperglucidic. It contains $64 \%$ carbohydrates, while those of Lefebvre and Luyckx [12], Hogan et al. [9] and Charles et al. [4], respectively, contain 47,50 and $48.3 \%$ carbohydrates. The paper of Buss et al. [8] does not give the exact composition of the breakfast test. By contrast our breakfast test contains less protein than the breakfast test of previous authors ( 9 vs $15 \%$ for Lefebvre and Luyckx [12] and Hogan et al. [9] and $21.7 \%$ for Charles et al. [4]). Compared to OGTT 
our breakfast test is markedly more insulinogenic [14], consistent with other authors who have also reported higher insulin responses in breakfast tests compared to OGTT [29]. However, Buss et al. [8] and Hogan et al. [9] showed similar insulin responses between breakfast and OGTT, and Charles et al. [4] a markedly lower response. In this study, we compared our hyperglucidic breakfast with a more classic mixed breakfast which has been designed to be similar to those of Charles et al. [4] and Hogan et al. [9]. This breakfast induces a higher increase in blood glucose, with no significant differences in insulin response. Thus, this hyperglucidic breakfast test seems to represent a higher glucose stimulus than the mixed meal. This fact is probably not explained by differences in the quantity of carbohydrates, since it has been demonstrated [30] that varying amounts of glucose between 25 and $100 \mathrm{~g}$ during an OGTT do not change the amplitude of blood glucose increase. Thus, the overall composition of the breakfast test is probably responsible for this higher hyperglycaemic effect. Such a difference in blood glucose response probably explains some of the discrepancies between our results and the negative results of previous investigators. Presumably, they employed meals which were too balanced to reproduce the conditions which lead to hypoglycaemia in this category of patients.

In conclusion, $47 \%$ of subjects in whom PRH was suspected had a blood glucose level lower than $3.3 \mathrm{mmol}$ during this breakfast test, i.e. values which could induce hypoglycaemic symptoms and neurological impairment. The occurrence of false positive responses which would be artefacts of the breakfast test (as occurs during OGTT) does not seem likely since subjects other than those assessed for suspicion of PRH had very few (1 to $2 \%$ ) low blood glucose levels after this test. Moreover, this test is fully physiological and mimics current nutritional habits, so that subjects who undergo hypoglycaemia during the test may also experience hypoglycaemia during their everyday life. However, this hyperglucidic breakfast possibly induced some false negative responses, i.e. several subjects with true PRH during their everyday life may fail to show a blood glucose value lower than $3.3 \mathrm{mmol}$ during this test. Nevertheless, we think that hyperglucidic physiological breakfasts such as the one presented here, fitting with normal nutritional habits, are a good alternative to ambulatory glycaemic testing for the diagnosing of $\mathrm{PRH}$, and are easier to perform.

\section{References}

1. Yager J, Young RT(1974) Non-hypoglycaemia is an epidemic condition. N Engl J Med 291:907-908

2. Cahill GJ Jr, Soeldner JS (1974) A non-editorial on nonhypoglycaemia. N Engl J Med 291:905-906
3. Lefèbvre PJ, Andreani D, Marks V, Creutzfeld W (1988) Statement on postprandial hypoglycaemia. Diabetes Care 11:439-440

4. Charles MA, Hofeldt F, Shackelford A (1981) Comparison of oral glucose tolerance tests and mixed meals in patients with apparent idiopathic post-absorptive hypoglycaemia. Diabetes 30:465-470

5. Lev Ran A, Anderson RW (1981) The diagnosis of postprandial hypoglycaemia. Diabetes 30:996-999

6. Johnson DD, Dorr KE, Swenson WM, Service FJ (1980) Reactive hypoglycaemia. JAMA 243:1151-1155

7. Palardy J, Havrankova J, Lepage R, Matte R, Bélanger R, D'Amour P, Ste-Marie LG (1989) Blood glucose measurements during symptomatic episodes in patients with suspected postprandial hypoglycaemia. N Engl J Med 321:1421-1425

8. Buss RW, Kawsal PC, Roddam RF (1982) Mixed meal tolerance test and reactive hypoglycaemia. Horm Metab Res 14:281-283

9. Hogan MJ, Service FJ, Shar Brougu FW, Gerich E (1983) Oral glucose tolerance test compared with a mixed meal in the hypoglycaemia. A caveat on simulation. Mayo Clinic Proc 58:491-496

10. Hofeldt F (1975) Reactive hypoglycaemia. Metabolism 24:1193-1208

11. Matthews DR, Hosker JP, Rudenski AS, Naylor BA, Treacher DF, Turner RC (1985) Homeostasis model assessment: insulin resistance and beta-cell function from fasting plasma glucose and insulin concentrations in man. Diabetologia 28:412-419

12. Lefèbvre PJ, Luyckx AS (1976) The breakfast tolerance test: a return to physiology. Diabetes Metab 2:15-19

13. Colloque de la Fondation Française pour la Nutrition (1981) L'évolution de l'alimentation des Français au cours des vingt dernières années. Médicine Nutrition 22:27

14. Orsetti A, Brun JF, Fédou C, Rodier M, Bouhaddioui L, Richard JL (1989) Etude de la glycorégulation à l'aide d'un petit déjeûner standardisé chez 21 obèses. Diabetes Metab 14:169

15. Luyckx AS, Lefebvre PJ (1971) Plasma insulin in reactive hypoglycaemia. Diabetes 20:435-442

16. Blackman JD, Towle VL, Sturis J, Lewis GF, Spire JP, Polonsky KS (1992) Hypoglycemic thresholds for cognitive dysfunction in IDDM. Diabetes 41:392-399

17. Cox DJ, Gonder-Frederick L, Clarke W (1993) Driving decrements in type I diabetes during moderate hypoglycaemia. Diabetes 42:239-243

18. Boyle P, Schwartz N, Shah S, Clutter W, Cryer P (1988) Plasma glucose concentrations at the onset of hypoglycaemic symptoms in patients with poorly controlled diabetes and in nondiabetes. N Engl J Med 318:1487-1492

19. Heller S, Herbert M, McDonald I, Tattersall R (1987) Influence of sympathetic nervous system on hypoglycaemic warning symptoms. Lancet II:259-263

20. Mitrakou A, Ryan C, Veneman Tet al. (1991) Hierarchy of glycaemic thresholds for counterregulatory hormone secretion, symptoms, and cerebral dysfunction. Am J Physiol 260 (Endocrinol Metab 23):E67-E74

21. Vea H, Jorde R, Sager G, Vaaler S, Sundsfjord J (1992) Reproducibility of glycaemic thresholds for activation of counterregulatory hormones and hypoglycaemic symptoms in healthy subjects. Diabetologia 35:958-961

22. Robinson AM, Moriarty KT, Parkin HM, Simpson EJ, Macdonald IA, Tattersall RB (1993) Increases in hypoglycaemic symptoms on standing wane, despite persisting physiological responses. Diabetologia 36:[Suppl]A150 (Abstract) 
23. Lefebvre PJ (1991) Hypoglycemia or non-hypoglycemia. In: Rifkin H, Colwell JA, Taylor SI (eds) Diabetes 1991. Proceedings of the 14th International Diabetes Federation Congress, Washington DC, USA, June 1991. Excerpta Medica Amsterdam London New York Tokyo, pp 757-761

24. Tamburrano G, Leonetti F, Sbraccia P, Giaccari A, Locuratolo N, Lala A (1989) Increased insulin sensitivity in patients with idiopathic reactive hypoglycemia. J Clin Endocrinol Metab 69:885-890

25. Brun JF, Orsetti A, Boegner C (1994). Exacerbation de l'assimilation glucidique mesurée par le minimal model dans les hypoglycémies réactionnelles. Diabetes Metab 20:3A (Abstract)

26. Foniciello M, Leonetti F, Giaccari A et al. (1992) Increased non- oxidative glucose metabolism and energy expenditure in idiopathic reactive hypoglycaemia. Diabetologia 35 [Suppl 1]:A187 (Abstract)
27. Kahn SE, Prigeon RL, McCulloch DK et al. (1993) Quantification of the relationship between insulin sensitivity and $\beta$-cell function in human subjects. Evidence for a hyperbolic function. Diabetes 42:1663-1672

28. Mirouze J, Orsetti A, Monnier L, Bringer J, Pham TC (1979) Les hypoglycémies tardives du diabète chimique: anomalies du glucagon pancréatique. Effects de la pectine. Diabetes Metab 5:279-285

29. Marena S, Montegrosso G, De Michieli F, Pisu E, Pagano G (1992) Comparison of the metabolic effects of mixed meal and standard oral glucose tolerance test on glucose, insulin and $\mathrm{C}$-peptide response in healthy, impaired glucose tolerance, mild and severe non-insulin-dependent diabetic subjects. Acta Diabetol 29:29-33

29. MacLean H, de Wesselow OLV (1921) The estimation of sugar tolerance. Q J Med 1921:103-119 